\title{
Malignering / Non Organic Tests - Are They Real?
}

\author{
George Ampat* \\ Consultant Orthopedic Spinal Surgeon, Feet and Spine, England \\ Submission: December 11, 2016; Published: December 19, 2016 \\ *Corresponding author: George Ampat, Consultant Orthopedic Spinal Surgeon, Feet and Spine, 309, Peter House, Oxford Road, Manchester M1 \\ 5AN, England, Email: george@feetandspine.com
}

\section{Introduction}

\section{The impact of chronic lower back pain}

Most of the general population will experience an episode of lower back pain at some point during their lifetime. Gross [1] described a lifetime prevalence of over $80 \%$ in a telephone survey and Cassidy [2] has reported that low-intensity/low disability back pain in the general population has a lifetime incidence of $84 \%$. Most rested and took painkillers but about $30 \%$ sought medical advice. Deyo [3] examined data from the second National Health and Nutrition Examination Survey and described that the cumulative lifetime prevalence of lower back pain lasting longer than 2 weeks was $13.8 \%$. Interestingly, the presentation varied according to age, gender, and educational status. Most rested with heat packs and reported that these helped.

Unfortunately some patients will develop chronic disabling back pain.

This has increased dramatically in recent years and Frymoyer [4] remarked that before the 20th century disabling back pain was rarely seen by the physician. Deyo's paper revealed that disabling low back pain was reported in $11 \%$ of the general population within the 6 month study period [5]. Similarly Von Korff's [6] review of the impact of back pain in primary care describes that $33 \%$ of patients continued to experience significant back pain 1 year after presentation and that 1 in 5 reported substantial activity limitation. It has also been acknowledged that many patients continue to experience chronic mild symptoms which do not interfere with daily activity. A thorough clinical examination is vital in the assessment of spinal pain. This paper provides a review of the Non Organic signs found in the current medical literature.

\section{Waddell's Signs}

Based on the systematic observation of 350 North American and British patients with low back pain, Waddell et al. [7] described and standardized nonorganic physical signs in low back pain. Waddell's nonorganic physical signs were proposed as a simple clinical screen to identify patients who may require more detailed assessment of psychological factors. There are five components to these tests and Waddell stated that isolated non organic signs should be ignored and significance attached to only to multiple positive signs from three or more of the five types.

\section{Tenderness}

a. Superficial: This sign is positive if the back pain is reproduced by lightly pinching the skin overlying the lumbar spine.

b. Non anatomic: Pain from the lumbar spine could be just limited to certain structures that are damaged. Any significant non anatomic enlargement of the area of tenderness is a positive response to this test.

\section{Simulation}

Simulation involves the performance of an examination manoeuvre that the patient believes may cause pain.

Axial loading: The presence of multiple articulations between the head and the lumbar spine should technically dampen any pressure applied axially over the skull. Reproduction of low back pain when applying an axial compression on the head is a positive response to this test.

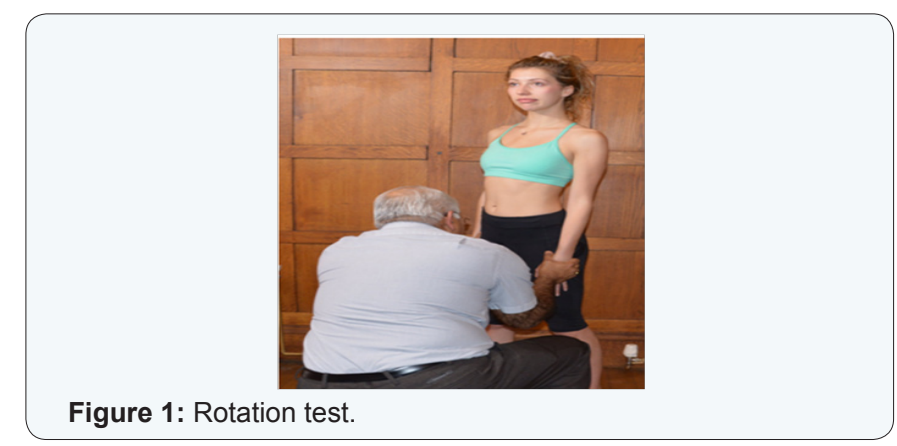

Rotation: Rotation of the trunk through the hips should technically not move the lumbar joints and hence should not cause any low back pain. To elicit the sign the examiner squats in front or behind the patient and holds the patient's hands / 
forearms onto the patient's trochanteric region. The examiner then suggests that the movement proposed to be undertaken may cause pain. The examiner then rotates the patient's pelvis. If the patient responds that this movement was painful then it is a positive response to this test (Figure 1).

\section{Distraction}

This involves observation of the same sign / test under different situations or conditions.

Straight leg rising: In the midst of the rest of the examination the examiner should attempt to inspect the patients lower back by requesting the patient to sit erect on the examination couch with the legs extended. If the patients straight leg raising is grossly restricted but if the patient is able to sit erect with the knee extended then it is a positive response to this test. This test can also be performed with the patient sitting on the couch with the legs hanging by the side. The examiner can then lift the foot up as if to determine the plantar reflex or sensation of the foot.

\section{Regional Neurological Deficit}

Monoradiculopathy should limit its effect only to the area supplied by the specific nerve root. A more wider area of involvement that is delineated by gross anatomical landmarks like the popliteal crease or the groin crease and which is not mirrored by known dermatomal patterns is suggestive of this sign.

Weakness: Weakness in one half of the body, the entire limb, or distal to the knee joint. The weakness may also be cogwheel in character with giving way.

Sensory disturbance: Sensory disturbance in a stocking pattern rather than a dermatomal pattern is a positive response to this test.

\section{Overreaction}

This involves disproportionate verbalization, facial expression, muscle tension and tremor, collapsing or sweating during examination.

\section{Other Behavioral Signs}

In addition to Waddells signs there are numerous behavioural signs described in medical literature. All these tests can be classified into three broad groups on similar lines as Waddell.

\section{Simulation tests}

i. Burns bench test

ii. Mcbride's test

iii. Kummel's neck movement

iv. Kummel's shoulder movement

v. Heel tap test.

vi. Plantar flexion of ankle at the limit of Straight Leg Raising

\section{Distraction tests}
a. Hoover's sign
b. O’Donoghue's manoeuvre

\section{Miscellaneous tests}

I. Mankopf's test

II. Pallesthesia

Burn's bench test [8]: The patient is asked to kneel on a padded surgical bench or a chair without arm supports. The patient is then instructed to flex the hips and knees to the maximum in order to achieve a position of being seated on one's calves. The patient then attempts to flex forward and touch the floor with fingertips. Flexion of the hip and knees should remove the stretch on the sciatic nerves and allow the patient to flex forward and touch the floor. An inability to flex or touch the floor is considered a positive response (Figure 2).

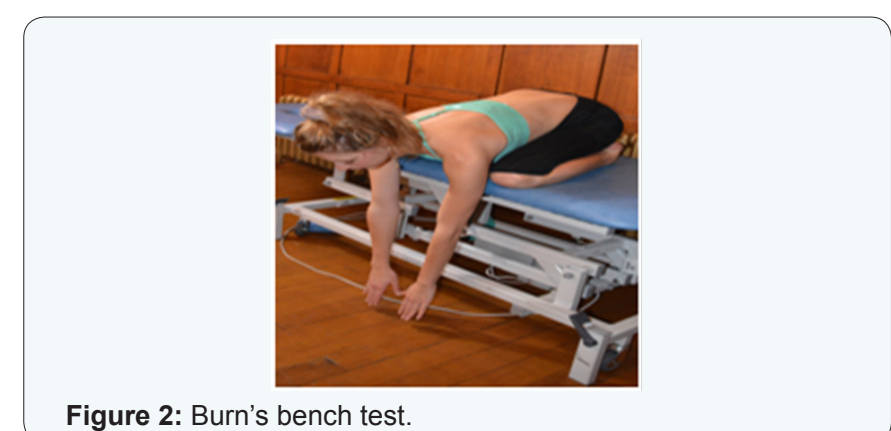

McBride's test [9]: The patient stand on both feet. The patient is then instructed to lift the affected leg and flex it at the hip and knee and to draw the knee close to the chest with hands. The flexion of the hip and the knees should remove the stretch on the sciatic nerve and off load the facet joints. A failure to perform the manoeuvre or reproduction of pain whilst performing the test is considered a positive response. In our practice we have found it safer to request the patient to lean on the wall whilst performing this test (Figure 3).

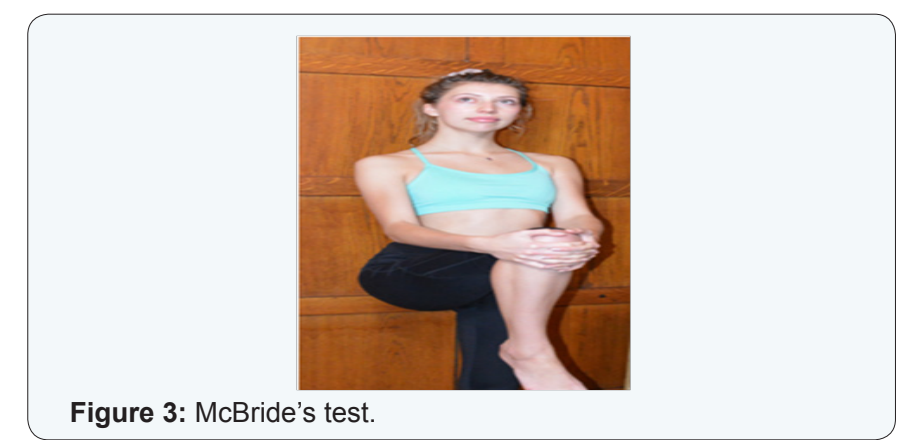

Kummel's neck movement [10]: The patient is asked to stand erect and move the neck in two different planes. Care should be taken to avoid any movement of the thoracic or lumbar spine when the patient is asked to move the cervical spine. This can be affected by the examiner placing a restraining hand on the chest to prevent such motion. The restraining hand 
however should not placed be over tender areas of the lower back. Reproduction of back pain whilst moving the neck in two different planes / directions is a positive response to this test.

Kummel's shoulder movement [10]: The patient is instructed to stand erect and to move each shoulder in turn. Care should be taken to avoid any movement of the lumbar spine whilst the patient attempts to move the shoulder. This can be achieved by the examiner placing a restraining hand on the trunk. This hand again should be placed on non tender areas. Limitation of movement and the production of pain on movement of the shoulder is a positive response to this test. If there is a minor degree of limitation of shoulder motion, less than $20^{\circ}$ in the selected plane, the test cannot be considered positive. The restriction must be present in more than one plane to be significant. The loss of shoulder motion is usually bilateral, but unilateral restrictions meeting the above criteria constitute an accepted nonorganic finding (Figure 4).

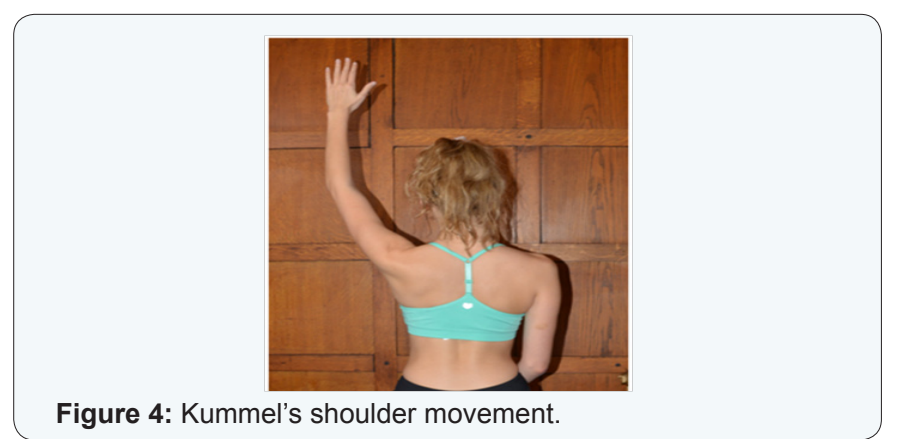

Heel Tap Test [11]: The patient is instructed to sit on the examination couch with hips and knees flexed to 90 degrees. The examiner suggests to the patient that the test may cause lower back pain. The examiner then lightly taps the patient's heel with the base of his hand. If the patient complains of sudden lower back pain, the test is considered to be positive (Figure 5).

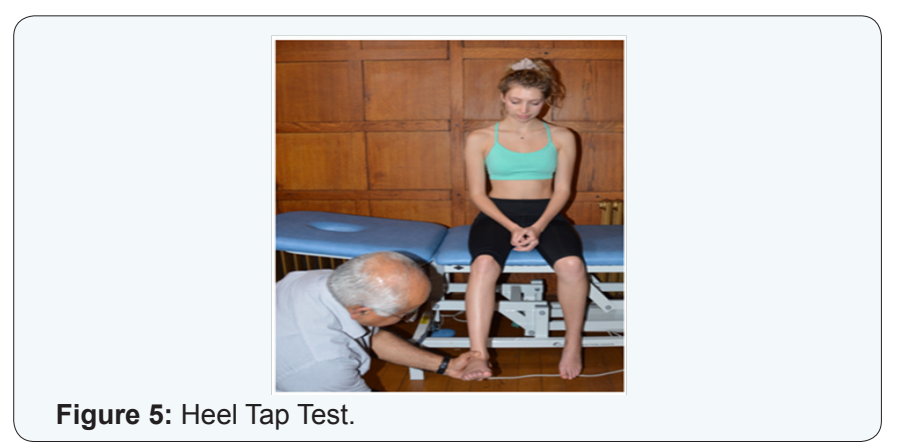

Plantar flexion of the ankle just prior to the limit of Straight leg raising test [12]: A standard straight leg raise test involves dorsiflexing the ankle. Instead of the standard dorsiflexion the foot is plantar flexed and the patient is asked whether he / she is experiencing leg pain. If plantar flexion causes or increases the pain then it is a positive result.

Hoover test [13]: The patient is made to lie supine in a relaxed manner. The examiner places both his / her hands on the couch under the heels of the patient. The patient is then instructed to perform an active straight leg raise on each leg. A patient putting genuine effort would cause counter pressure on the contralateral heel i.e. when attempting to lift the left leg a genuine patient putting effort would force the right heel to dig into the couch or the examiners palm. A lack of counter pressure is a positive result suggesting an absence of effort by the patient. The patient may think that the leg that is being elevated is being tested.

0'Donoghue's Manoeuvre [9]: In patients with genuine pathology passive range of motion is always greater than active range of motion. The test is positive if the active range of motion is greater than the passive range of motion.

Mankopf's test [9]: Production of noxious stimuli has an autonomic effect on the cardiovascular system by increasing the pulse rate. Mankopf's tests suggest that palpation of the painful lumbar spine should under normal circumstances increase the pulse rate by about $5 \%$. If there is no concomitant increase of the pulse rate as seen by a pulse oximeter whilst there is firm pressure applied on the painful lumbar spine the test is considered positive.

Pallesthesia [12]: Pallesthesia is defined as the lack of vibration sensibility. Vibration sensation is conducted to wide areas through the bone and there is also considerable overlap of dermatomes. Hence damage to a single nerve root should not cause any difference in the perception of vibration sensation. Any altered sensation of vibration that is not accompanied by other signs of general neurological disorder is a positive response to this test.

\section{Discussion}

Assessment of low back pain is a complex task. A proper history and thorough examination reassures the patient. Though thorough psychological testing cannot be substituted with a physical examination the presence of so called behavioral signs should alert the physician. Controversy and debate has raged over these behavioral signs for the last 28 years since originally described by Waddell.

There are concerns regarding the Waddell signs. Are they reproducible? Is the clinician relying on them as a screening tool for malingering? Are patients being refused appropriate treatment because they might have exhibited some of these signs? Are patients being denied their due compensation again because they demonstrated some of these signs? Waddell himself acknowledges that the signs are poorly recognized [14,15] and that have been "misinterpreted and misused both in clinical contexts and in medico legal assessment".

Waddell [16] categorically states that these signs only act as a crude psychological assessment and should not be used as an indication of malingering. Patients exhibiting these signs require further work up. They are not to be denied appropriate 


\section{Orthopedics and Rheumatology Open Access Journal}

treatment which may include surgical intervention. Waddell also states that whilst over-reaction is the single most reliable sign this was unfortunately also the sign most vulnerable to subjective influence of the examiner [17].

Fishbain et al. [18] agrees that the presence of Waddell's signs does represent poor surgical prognosis, higher degrees of pain, and decreased functional performance, they caution that the reproducibility and reliability of such signs in lower back pain is poor. They state that the Waddell signs are not reliable indicators of psychologic distress or malingering.

Polatin [19] has cast doubt upon the prognostic value of Waddell's signs and has suggested that they correlate poorly with functional improvement following multidisciplinary rehabilitation. It is also important to appreciate that careful consideration of the significance of Waddell's signs should be used in the elderly patient and when signs occur in isolation.

Centano [20] questions the authenticity of Waddell's signs with current knowledge of neuropathic pain. They state that in neuropathic pain mechanical hyperalgesia and tactile hypersensitisation is common. They also state that the "windup" mechanism following neuronal injury can lead to grossly exaggerated response to stimuli and increase the size of the receptive field on the skin. This thereby questions the validity of the signs of non anatomic / superficial tenderness, regional weakness / sensory disturbance and over reaction.

Kummel described how Waddells signs along with the two new signs described by him improved the reliability of predicting not returning to work from $52.9 \%$ to $73.1 \%$. Gaines [21] stated that patients with acute back pain exhibiting Waddells signs, in the occupational health setting had a four times lengthier returned to work than those not exhibiting the signs. Hayes [22] examining those patients expecting compensation for their back pain predicted $90 \%$ of cases with Waddell's nonorganic signs.

Slipman [23] demonstrated the difference between dynatomal and dermatomal maps. Dynatomes were areas affected when the nerve root was irritated. Dermatome on the contrary was areas that lost sensation when the nerve root was severed. Dynatome were larger and did not match with dermatomes. It is thus possible that when a single nerve root is affected the dynatome is affected and the effect is thus not limited to dermatomes.

Wadell's original study stated that there was a clear correlation between non organic signs and the neurotic triad of MMPI (Minnesota Multiphasic Personality Inventory). In contrast to the original study Maruta et al. [24] showed no significant correlation between Waddell scores and Depression among male patients while there were some statistically significant differences for scales of Hypochondriases and Hysteria. Among female patients there was no correlation between MMPI scales of Hypochondriasis, Depression or Hysteria with the Waddell score. A statistically significant correlation among and men and women was found only on scale 8 (Schizophrenia). This shows increased awareness of interpersonal discomfort and self-absorbed ways of experiencing and expressing pain among those with high Waddell scores.

Waddell [17] states, patients are not just cases of disturbed pathology or mechanics or neurophysiology, they are suffering human beings. When patients gain the impression that the examining clinician thinks the patient is putting on symptoms and signs, this does a tremendous disservice to patients and actually magnifies their entire pain perception; this results in despair and psychologic difficulties when trying to cope with what they consider to be their very real pain.

\section{Summary}

The impact upon the healthcare system of chronic disabling lower back pain with no discernable organic cause is vast, consuming not only the time of healthcare professionals but also ineffectual investigations and treatments. The key for the medical practitioner is to develop a repertoire of examination techniques allowing a distinction between patients who are at risk of developing disabling lower back pain and would instead benefit from psychological support.

There are multitudes of specialist examination tests described in the literature which, if used carefully, will help in this process. This paper consolidates these tests describing their methodology so that a medical practitioner can complete them in the outpatient setting. Equally patients with low back pain most simply value a doctor prepared to listen to their views!

\section{References}

1. Gross DP, Ferrari R, Russell AS, Battie MC, Schopflocher D, et al. (2006) population-based survey of back pain beliefs in Canada. Spine (Phila Pa 1976) 31(18): 2142-2145.

2. Cassidy JD, Carroll LJ, and Cote P (1998) The Saskatchewan health and back pain survey. Spine (Phila Pa 1976) 23(17): 1860-1867.

3. Deyo RA, Tsui-Wu YJ (1987) Descriptive epidemiology of low back pain and its related medical care in the United States. Spine (Phila Pa 1976) 12(3): 264-268.

4. Frymoyer JW (1992) Predicting disability from low back pain. Clin Orth Relat Res 279: 101-109.

5. Deyo RA, Rainville J, Kent DL (1992) What can the history and physical tell us about low back pain? JAMA 268(6): 760-765.

6. Von Korff Michael, Saunders Kathleen JD (1996) The course of back pain in primary care. Spine (Phila Pa 1976) 21(24): 2833-2837.

7. Waddell G, McCulloch JA, Kummel E, Venner RM (1980) Nonorganic physical signs in low back pain. Spine (Phila Pa 1976) 5(2): 117-125.

8. Nehemkis AM, Carver DW, Evanski PM (1979) The predictive utility of the orthopedic examination in identifying the low back pain patient with hysterical personality features. Clin Orthop Relat Res 145: 158162.

9. Kiester PD, Duke AD (1999) Is it malingering, or is it 'real'? Eight signs that point to nonorganic back pain. Postgrad Med 106(7): 77-80, 8384.

10. Kummel BM (1996) Nonorganic signs of significance in low back pain. Spine (Phila Pa 1976) 21(9): 1077-1081. 
11. Blom A, Taylor A, Whitehouse S, Orr B, Smith E (2002) A new sign of inappropriate lower back pain. Ann R Coll Surg Engl 84(5): 342-343.

12. Centeno CJ, Elkins WL, Freeman M (2004) Editorial. Waddell's signs revisited? Spine (Phila Pa 1976) 29(13): 1392.

13. Koehler PJ, Okun MS (2004) Important observations prior to the description of the Hoover sign. Neurology 63(9): 1693-1697.

14. Macrae IF, Wright V (1969) Measurement of back movement. Ann Rheum Dis 28(6): 584-589.

15. Waddell G, Main CJ (1984) Assessment of severity in low-back disorders. Spine (Phila Pa 1976) 9(2): 204-208.

16. Main CJ, Waddell G (1998) Behavioral Responses to Examination: A Reappraisal of the Interpretation of "Nonorganic Signs". Spine (Phila Pa 1976) 23(21): 2367-2371.

17. Waddell G. The Back Pain Revolution. 2nd ed. Edinburgh: Churchill Livingstone; 2004. Overreaction should be dropped as it is prone to observer bias and unrealiability.

18. Fishbain DA, Cole B, Cutler RB, Lewis J, Rosomoff HL, et al. (2003) A structured evidence-based review on the meaning of non-organic physical signs: Waddell signs. Pain Med 4(2): 141-181.
19. Polatin PB, Cox B, Gatchel R, Mayer TG (1997) A Prospective Study of Waddell Signs in Patients With Chronic Low Back Pain: When They May Not Be Predictive. Spine (Phila Pa 1976) 22(14): 1618-1621.

20. Centeno CJ, Elkins WL, Freeman M (2004) Waddell's signs revisited? Spine 29(13): 1392- 1393.

21. Gaines WG and Hegmann KT (1999) Effectiveness of Waddell's Nonorganic Signs in Predicting a Delayed Return to Regular Work in Patients Experiencing Acute Occupational Low Back Pain. Spine (Phila Pa 1976)24(4): 396-400.

22. Hayes B, Solyom C, Wing P, and Berkowitz J (1993) Use of psychometric measures and nonorganic signs testing in detecting nomogenic disorders in low back pain patients. Spine (Phila Pa 1976) 18(10): 1254-1259.

23. Slipman CW, Plastaras CT, Palmitier RA, Huston CW, Sterenfeld EB (1998) Symptom provocation of fluoroscopically guided cervical nerve root stimulation: are dynatomal maps identical to dermatomal maps? Spine (Phila Pa 1976) 23: 2235-2242.

24. Maruta T, Goldman S, Chan CW, Ilstrup D, Kunselman A, et al. (1997) Waddell's Nonorganic Signs and Minnesota Multiphasic Personality Inventory Profiles in Patients With Chronic Low Back Pain. Spine 22(1): 72-75.

Your next submission with JuniperPublishers
will reach you the below assets
- Quality Editorial service
- Swift Peer Review
- Reprints availability
- E-prints Service
- Manuscript Podcast for convenient understanding
- Global attainment for your research
- Manuscript accessibility in different formats
( Pdf, E-pub, Full Text, A udio)
- Unceasing customer service
Track the below URL for one-step submission
http://juniperpublishers.com/online-submission.php

